\title{
ESTUDO COMPARATIVO DOS MÉTODOS DE ULTRA-SONOGRAFIA, TOMOGRAFIA COMPUTADORIZADA E RESSONÂNCIA MAGNÉTICA NO ESTADIAMENTO E INVASÃO DAS ESTRUTURAS ADJACENTES POR TUMORES RENAIS
}

\author{
S.M. Ribeiro*, S.A. Ajzen, J .C.S. Trindade
}

Faculdade de Medicina da Universidade Federal de São Paulo (UNIFESP) e Faculdade de Medicina da Universidade Estadual Paulista "Júlio de Mesquita Filho" (UNESP), S. Paulo, SP.

RESUMO - OBjetivo. Comparamos os exames de ultra-som (US), tomografia computadorizada (TC) e ressonância magnética (RM) no estadiamento dos tumores renais, estudando as diferenças entre estes exames em relação a sua capacidade de detecção de adenomegalias, invasão vascular, metástases intra-abdominais à distância e particularmente invasão dos órgãos adjacentes.

Métodos. Foram estudados prospectivamente 31 pacientes portadores de massas renais sólidas ou complexas através dos exames de US, TC e RM. As discordâncias entre os resultados observados foram estudadas através do Teste $\mathbf{G}$ de Cochran e Teste de McNemar, além de se calcular a sensibilidade e especificidade de cada método diagnóstico utilizado, considerando-se como "regra de ouro" os achados cirúrgico e anatomopatológico.

Resultados. Destes 31 pacientes, 28 eram portadores de massas malignas e três de lesões benignas. Quanto à detecção de adenomegalia, o US mostrou sensibilidade de $63,6 \%$, enquanto a TC e RM tiveram sensibilidade de $90,9 \%$. Em relação à invasão vascular, o US mostrou sensibilidade de $42,8 \%$ enquanto que a TC e a RM tiveram a sensibilidade de $85,7 \%$. Em relação à invasão de órgãos adjacentes, a sensibilidade foi respectivamente $28,5 \%$ (US), $85,7 \%$ (TC) e $71,4 \%$ (RM). São critérios que sugerem a invasão das estruturas adjacentes: quando estas se encontram envolvidas/englobadas pelo tumor; a extensão do tumor para 0 seu interior com superfície de contato irregular; alteraçōes na forma, tamanho e densidade da estrutura adjacente. Somente a perda do plano de gordura e o íntimo contato do tumor com a estrutura adjacente não indicam invasão.

ConclusöEs. Houve diferenças significantes na capacidade de detecção do US em relação à TC e RM. Estas duas últimas não diferiram entre si. Somente em relação às metástases abdominais à distância todos os métodos se mostraram altamente sensíveis e espećficicos. Além da acurácia dos métodos, tanto para o diagnóstico como no estadiamento, devem ser considerados aspectos relativos à invasibilidade, riscos e preço na ponderação dos custos e benefícios dos diversos exames de diagnóstico por imagem.

Unitermos: Tumores renais. Estadiamento. Diagnóstico por Imagem. Tomografia Computadorizada por raios X. Ressonância Magnética. Ultra-som.

\section{INTRODUÇÃo}

Realizamos um estudo prospectivo em 31 pacientes adultos portadores de massas renais sólidas ou complexas submetidos aos exames de ultra-sonografia abdominal (US), tomografia computadorizada (TC) e ressonância magnética (RM) com o intuito de

\footnotetext{
*Correspondência:

Sérgio M. Ribeiro

Rua Nelo Pedretti, 420 - Chácara Barros

Botucatu - SP - Cep: 18609-030 - Tel.: (14) 6822-2757

Fax: (14)6822-1930 - E-mail: sribeiro@fmb.unesp.br
}

verificar o melhor caminho a seguir em termos do estadiamento das massas renais sólidas e complexas, analisando os critérios de acurácia, riscos e invasibilidade dos diversos métodos de diagnóstico por imagem, assim como procuramos estabelecer critérios de invasibilidade de tumores grandes em estadio avançado, oque é de grande importância na conduta terapêutica!.

\section{Métodos}

Foi realizado um estudo prospectivo de março de 1994 a outubro de 1996 em 37 pacientes portadores de massas sólidas ou complexas, suspeitadas clinicamente ou descobertas pela realização de algum exame de diagnóstico por imagem e encaminhados ao nosso serviço. Destes 37 pacientes, seis foram excluídos do trabalho ou por não ter um diagnóstico final conclusivo ou em função do protocolo ter ficado incompleto, impossibilitando a análise estatística dos dados. Todos os demais 31 pacientes foram estudados através de US, TC e RM realizados segundo o protocolo abaixo descrito. 
Dos 31 pacientes estudados, 20 eram do sexo masculino e I I do sexo feminino, com idades variando de 31 a 85 anos e idade média de 58,2 anos.

O ultra-som abdominal foi avaliado por dois radiologistas nos aparelhos ATL (Ultramark 9, USA) e Toshiba (Sonolayer SSHI 40 A/G, Japan).

Os exames de tomografia computadorizada foram realizados em aparelhos marca Siemens (Somatom DR G, Germany); Schimadzu (SCT-4500T, Japan) e General Eletric (CT 9800, USA).

$\mathrm{Na}$ tomografia computadorizada estabeleceu-se a realização de cortes de 5 $\mathrm{mm}$ de espessura por $5 \mathrm{~mm}$ de incremento na altura dos rins na fase sem contraste, e $10 \mathrm{~mm}$ de espessura por 10 $\mathrm{mm}$ de incremento em todo abdômen, até o nível logo abaixo da bifurcação da aorta na fase contrastada, quando foi injetado cerca de 100 a $160 \mathrm{ml}$ de contraste iodado a $60 \%$. Previamente ao início do exame, foi também ministrado contraste via oral, para contrastação das alças intestinais.

Os exames de ressonância magnética foram realizados nos aparelhos marca Philips (Gyroscan S- I 5 HP de I, 5 Tesla, Neederland) e General Eletric-CGR (MR MAX de 0,5 Tesla, France).

Na ressonância magnética utilizou-se faixa de compressão abdominal ou compensador de movimentos respiratórios para minimizar artefatos de movimento. Foram realizados, no nível dos rins, cortes nas seqüências: "Spin - Echo" ponderada em TI no plano axial, sem contraste e no plano coronal, após a injeção intravenosa de gadolíneo. Compreendendo todo o abdômen, até a bifurcação da aorta, foram realizadas as seqüências "Spin - Echo" ponderada em T2 e Densidade de Prótons (DP) e "Spin - Echo" ponderada em TI no plano axial, após a injeção de 10 a $15 \mathrm{ml}$ de contraste intravenoso (gadolíneo). Os cortes foram realizados com 5 a $10 \mathrm{~mm}$ de espessura, tanto nos planos coronal como axial. Em função de uso de equipamento de
0.5 T, não foi possível a realização de sequêencias rápidas, como imagens Gradient Echo segurando a respiração durante a injeção dinâmica do gadolíneo.

No estadiamento destes pacientes ainda foram realizadas radiografias de tórax. Outros exames de diagnóstico por imagem, como TC do tórax, radiografias de ossos, etc., só foram realizados em casos específicos onde estes exames foram indicados.

Os exames de diagnóstico por imagem foram analisados detalhadamente tanto em relação aos aspectos do diagnóstico como do estadiamento das lesões, procurando se caracterizar a densidade da massa em relação ao parênquima renal normal, os contornos, dimensões, localização e a presença ou não de calcificações. Quanto à extensão da massa, anotou-se a presença ou não de invasão da gordura perirenal, das estruturas adjacentes, da veia renal e veia cava inferior, adenomegalias hilares e retroperitoneais, utilizando-se 0 estadiamento de Robson². Foram também anotadas alterações no sistema pielocalicial, invasão do seio renal e a presença de outras lesões tais como metástases ósseas, hepáticas, ascite, etc.

Dois médicos radiologistas preencheram os dados separadamente, em protocolo previamente estabelecido, sem o conhecimento dos resultados dos outros exames. Nos poucos casos onde ocorreu discordância dos achados, os exames foram submetidos à análise de um terceiro radiologista, obtendo-se assim uma posição final que foi posteriormente comparada com os achados cirúrgicos e anatomopatológicos.

O presente trabalho foi aprovado pela Comissão de Ética Médica e houve consentimento dos pacientes para a realização dos exames.

\section{Análise Estatística}

Para a análise dos resultados foram utilizados os seguintes testes não-paramétricos, levando-se em consideração a natureza das variáveis estudadas:
I - Teste G de Cochran ${ }^{3}$ com o objetivo de estudar as discordâncias entre os resultados observados com o US, TC e RM para a detecção de adenomegalia, invasão vascular, invasão de órgãos adjacentes e metástases intra-abdominais à distância.

2 - Teste de McNemar ${ }^{4}$ com a finalidade de estudar as discordâncias entre os exames de TC e RM na detecção de invasão da gordura peri-renal.

Além dos testes estatísticos assinalados, calcularam-se a sensibilidade e a especificidade de cada um, considerandose como "regra de ouro" os achados cirúrgico e anatomopatológico. Nos pacientes não operados e com metástases à distância, a maioria dos achados foram concordantes nos diversos métodos diagnósticos e foram considerados verdadeiros, assim como a ausência de outras lesões associadas também foi um achado concordante e considerado verdadeiro no paciente com pseudo-tumor, também não operado. Onde esta concordância de achados não ocorreu, o paciente foi descartado da análise em questão. Isto aconteceu em somente dois pacientes com metátases à distância onde este achado não foi concordante em todos os exames.

Em todos os testes fixou-se em 0,05 ou $5 \%$ o nível para a rejeição da hipótese de nulidade, assinalando-se com um asterisco os valores significantes.

\section{Resultados}

Dos 3 I pacientes que entraram no presente estudo, 20 eram do sexo masculino e I I do sexo feminino. A idade variou de 3 | a 85 anos, com média de 58,2 anos, sendo 27 da raça branca, dois da amarela e dois da raça negra. Os principais achados clínicos estão relacionados na tabela I.

Quanto ao diagnóstico final desses pacientes, 28 eram portadores de massas malignas e três de lesões benignas. Das 28 massas malignas, 20 eram carcinomas de células renais, três carcinomas de células transi- 
cionais e cinco ficaram sem o diagnóstico histopatológico final, já que em três destes pacientes os tumores foram cirurgicamente irressecáveis e os outros dois tinham metástases à distância, contra-indicando a cirurgia. Dentre os 23 pacientes portadores de massas malignas, o diagnóstico final de 21 deles foi obtido através de cirurgia e posterior exame anatomopatológico. Em um caso o diagnóstico foi realizado por biópsia da metástase pulmonar e em outro após cirurgia e exame histopatológico de metástase cerebral, esta última responsável pelas primeiras manifestações clínicas do paciente. As três lesões benignas ficaram com o diagnóstico de um hematoma em organização, um mixoma e um pseudotumor, as duas primeiras diagnosticadas através de cirurgia e exame anatomopatológico e a última comprovada pelo seguimento clínico e radiológico do paciente.

As dimensões das massas estão relacionadas na tabela 2.

Os dados relativos ao estadiamento encontrados pelos diversos métodos de diagnóstico por imagem foram comparados entre si através do Teste $G$ de Cochran, Teste de McNemar e de estudos de sensibilidade e especificidade, que são apresentados resumidamente nas tabelas 3,4,5 e 6 .

A invasão da gordura peri-renal foi estudada através da TC e RM, obtendo-se os resultados mostrados nas tabelas 6 e 7 .

O teste $G$ de Cochran não mostrou discordância significante entre os métodos de diagnóstico por imagem no que diz respeito à detecção de metástasesà distância para órgãos intra-abdominais (tabela 5). Tanto o US como a TC e RM detectaram os cinco casos de metástases intra-abdominais à distância e também mostraram corretamente a ausência destas lesões nos outros pacientes, apresentando todos eles uma sensibilidade e uma especificidade de quase 100\%, achados estes que se correlacionam bem com os descritos na literatura que referem uma elevada acurácia do US, TC e RM na detecção de metástases intra-abdominais à distância $a^{5,6,7}$.

Destes cinco pacientes, três apresenta-

Tabela I - Achados clínicos dos 3 I pacientes portadores de massas renais.

\begin{tabular}{lcc}
\hline Achadosclínicos & Número de pacientes $(\mathbf{n})$ & Porcentagem de pacientes (\%) \\
Hematúria & 21 & 67,7 \\
Dorabdominal & 16 & 51,6 \\
Massa palpável & 11 & 35,5 \\
Emagrecimento & 14 & 45,1 \\
Anemia & 16 & 51,6 \\
\hline
\end{tabular}

Tabela 2 - Dimensões das massas renais.

\begin{tabular}{ccc} 
Tamanho $(\mathbf{c m})$ & $\mathbf{N} .^{\circ}$ de massas & $\%$ \\
Menor que 3 & 2 & 6,4 \\
3, I a 6,0 & 6 & 19,3 \\
6, I a I0,0 & 8 & 25,8 \\
I0, I a | |8,0 & 11 & 35,5 \\
|8, I ou maior & 4 & 12,9 \\
Total & 31 & 100,0 \\
\hline
\end{tabular}

ram metástases hepáticas e dois apresentaram metástases para o rim contralateral. Os cinco apresentaram ainda outras metástases hematogênicas associadas: pulmonares (dois casos), ósseas (dois casos), pleural (um caso) e para o sistema nervoso central (um caso).

As metástases ósseas eram todas osteolíticas e evidenciadas na coluna, sacro e costelas em um paciente e na cabeça do úmero num segundo paciente. Um dos pacientes apresentou metástases para 0 mediastino na forma de linfonodomegalias, além de um quadro radiológico muito sugestivo de linfangite carcinomatosa nas regiões pulmonares peri-hilares.

Os resultados relacionados aos aspectos exclusivos do diagnóstico destas lesões serão apresentados em outro artigo e não serão aqui discutidos.

\section{Discussão}

\section{Adenomegalia}

O teste $\mathrm{G}$ de Cochran mostrou discordância significante entre os métodos de diagnóstico por imagem no que diz respeito a detecção de adenomegalia. Mostrou que o US apresentou uma capacidade de detecção significativamente menor que a TC e RM, que não diferiram entre si. Em somente um de II pacientes não foidetectada adenomegalia nem pela TC nem pela RM. Neste caso, a cirurgía detectou pequenos gânglios, de aproximadamente $1 \mathrm{~cm}$ de diâmetro, em hilo renal e retrocava, e o exame anatomopatológico mostrou que três destes gânglios estavam envolvidos por carcinoma de células renais.

A maioria dos erros foram de casos falso-positivos, principalmente pela TC, o que resultou em uma maior especificidade da RM. Houve confusão pela TC de gânglios com vasos colaterais em hilo renal, com veia gonadal esquerda proeminente e com a porção final da crura diafragmática direita, que normalmente apresenta inserção mais baixa que a cúpula diafragmática esquerda. $\mathrm{Na} R M$ confundimos uma alça intestinal com um gânglio aumentado.

Estes achados são compatíveis com os descritos pela literatura, que referem não ser o US método acurado no estadiamento do carcinoma de células renais, principalmente em função do gás intestinal que 
Tabela 3 - Pacientes portadores de massas renais segundo a presença (+) ou ausência (-) de adenomegalia, invasão vascular, invasão de órgãos adjacentes e metástases intra-abdominais à distância detectada pelo ultra-som (US), tomografia computadorizada $(\mathrm{TC})$ e ressonância magnética $(\mathrm{RM})$ *.

\begin{tabular}{|c|c|c|c|c|c|c|c|c|c|c|c|c|}
\hline \multirow[b]{2}{*}{ Paciente } & \multicolumn{3}{|c|}{ Adenomegalia } & \multicolumn{3}{|c|}{ Invasão vascular } & \multicolumn{3}{|c|}{$\begin{array}{l}\text { Invasão de órgãos } \\
\text { adjacentes }\end{array}$} & \multicolumn{3}{|c|}{$\begin{array}{l}\text { Metástases intra- } \\
\text { abdominais }\end{array}$} \\
\hline & US & $\mathrm{TC}$ & RM & US & $\mathrm{TC}$ & RM & US & $\mathrm{TC}$ & RM & US & $\mathrm{TC}$ & RM \\
\hline 01 & - & - & - & - & - & - & - & - & - & - & - & - \\
\hline 02 & + & + & + & + & + & + & - & + & - & - & - & - \\
\hline 03 & - & + & + & - & - & - & - & - & - & + & + & + \\
\hline 04 & + & + & + & + & + & + & - & + & + & - & - & - \\
\hline 05 & t & + & t & - & - & - & - & - & - & - & - & - \\
\hline 06 & - & - & - & - & - & - & - & - & + & - & - & - \\
\hline 07 & + & + & + & - & + & + & + & + & + & - & - & - \\
\hline 08 & - & - & - & - & - & - & - & - & - & - & - & - \\
\hline 09 & - & - & - & - & - & - & - & - & - & - & - & - \\
\hline 10 & - & - & - & - & - & - & - & - & - & - & - & - \\
\hline 11 & - & - & - & - & - & - & - & - & - & - & - & - \\
\hline 12 & - & + & + & - & - & - & - & - & - & - & - & - \\
\hline 13 & - & - & - & - & - & - & - & - & - & - & - & - \\
\hline 14 & + & + & + & - & - & - & - & - & - & - & - & - \\
\hline 15 & - & - & - & - & - & - & - & - & - & - & - & - \\
\hline 16 & - & + & - & - & - & - & - & - & - & - & - & - \\
\hline 17 & - & + & - & - & - & - & - & + & + & - & - & - \\
\hline 18 & - & - & + & - & - & - & - & - & - & - & - & - \\
\hline 19 & - & + & + & - & - & - & - & - & - & - & - & - \\
\hline 20 & + & + & + & - & + & + & - & - & - & - & - & + \\
\hline 21 & + & + & + & - & + & + & & + & + & + & + & + \\
\hline 22 & - & + & - & - & - & - & - & - & - & - & - & - \\
\hline 23 & - & - & - & - & - & - & - & - & - & + & + & + \\
\hline 24 & - & - & - & - & - & - & - & + & + & - & - & - \\
\hline 25 & - & + & - & - & - & - & - & - & - & - & - & - \\
\hline 26 & - & + & + & + & + & + & - & + & - & - & + & - \\
\hline 27 & - & - & - & - & + & + & - & + & - & - & - & - \\
\hline 28 & - & - & - & - & - & - & - & - & - & + & + & + \\
\hline 29 & - & - & - & - & - & - & - & - & - & - & - & - \\
\hline 30 & - & - & - & - & - & - & + & + & + & + & + & + \\
\hline 31 & - & - & - & - & - & - & - & - & - & - & - & - \\
\hline $\begin{array}{l}\text { Total + } \\
\%+\end{array}$ & $\begin{array}{c}7 \\
22,0\end{array}$ & $\begin{array}{c}15 \\
48,4\end{array}$ & $\begin{array}{c}12 \\
38,7\end{array}$ & $\begin{array}{c}3 \\
9,7\end{array}$ & $\begin{array}{c}7 \\
22,6\end{array}$ & $\begin{array}{c}7 \\
22,6\end{array}$ & $\begin{array}{c}2 \\
6,4\end{array}$ & $\begin{array}{c}9 \\
29,0\end{array}$ & $\begin{array}{c}7 \\
22,6\end{array}$ & $\begin{array}{c}5 \\
16,1\end{array}$ & $\begin{array}{c}6 \\
19,3\end{array}$ & $\begin{array}{c}6 \\
19,3\end{array}$ \\
\hline
\end{tabular}

- Gânglio considerado aumentado quando maior ou igual a I cm no seu maior diâmetro. Foram excetuadas metástases para supra renal ipsilateral e metástasesósseas

freqüentemente obscurece o retroperitôneo central, dificultando a avaliação da extensão tumoral para linfonodos retroperitoneais em cerca de $50 \%$ dos pacientes ${ }^{8,5,9}$.

A TC detecta acuradamente aumento de linfonodos retroperitoneais centrais e retrocavais. A sensibilidade da TC no esta- diamento dos linfonodos relatada é de 83 a $89 \%$ 6, 10,7

A TC diferencia melhor os linfonodos das alças intestinais, mas a RM demonstra mais claramente as diferenças teciduais entre a crura diafragmática, vasos e linfonodos. Entretanto, nem a RM nem a TC podem demonstrar a presença de neoplasia em nódulos de tamanho normal ou confiavelmente indicar a causa do aumento do linfonodo, distinguindo linfoadenopatia reacional benigna de metástases microscópicas, dependendo dos critérios do tamanho e número na avaliação dos linfonodos ${ }^{11,12,7}$. 
Tabela 4 - Sensibilidade e especificidade do ultra-som (US), tomografia computadorizada (TC) e ressonância magnética (RM) na detecção da presença ou ausência de adenomegalia ${ }^{*}$, invasão vascular e invasão de órgãos adjacentes nos pacientes portadores de tumores renais*.

\begin{tabular}{llccc}
\hline & & US & TC & RM \\
\cline { 3 - 4 } ADENOMEGALIA & SENSIBILIDADE & $63,6 \%$ & $90,9 \%$ & $90,9 \%$ \\
& ESPECIFICIDADE & $100,0 \%$ & $75,0 \%$ & $90,0 \%$ \\
INVASÃOVASCULAR & SENSIBILIDADE & $42,8 \%$ & $85,7 \%$ & $85,7 \%$ \\
& ESPECIFICIDADE & $100,0 \%$ & $95,8 \%$ & $95,8 \%$ \\
INVASÃODEÓRGÃOSADJACENTES & & & $71,4 \%$ \\
\hline
\end{tabular}

"gânglio considerado aumentado quando maior ou igual a I cm no seu maior diâmetro.

Opresente estudo confirma os achados da literatura mostrando a alta sensibilidade tanto da TC quanto da RM na detecção de adenomegalias e que existe uma pequena superioridade da RM na distinção das diferentes estruturas, particularmente os vasos dos linfonodos. Já em relação às alças intestinais, um bom preparo com a ingestão de contraste torna as alças intestinais mais facilmente distinguíveis dos gânglios linfáticos pela TC do que pela RM, onde este preparo intestinal não é feito.

\section{Invasão vascular}

O teste $\mathrm{G}$ de Cochran mostrou discordância significante entre os métodos de diagnóstico por imagem no que diz respeito à detecção de invasão vascular. Mostrou que - US apresentou uma capacidade de detecção significativamente menor do que a TC e a RM, que não diferiram entre si.

O US detectou acertadamente os dois casos onde a invasão da veia cava se estendia até a sua porção proximal, retrohepática, e em um caso onde só havia invasão da veia renal. Dos quatro casos onde não identificou invasão venosa, houve dificuldade na visualização da veia renal e porção baixa da veia cava inferior em função destes vasos estarem rechaçados e comprimidos por volumosa massa renal, por importantes adenomegalias periaorta e veia cava, assim como a presença de gases em alças
Tabela 5 - Teste g de Cochran - estudo das discordâncias entre os resultados observados com o ultra-som, tomografia computadorizada e ressonância magnética para a detecção de adenomegalia, invasão vascular, invasão de órgãos adjacentes e metástases intra-abdominais à distância. Assinalou-se com um asterisco os valores significantes.

\begin{tabular}{lcccc}
\hline $\begin{array}{c}\text { Adeno- } \\
\text { megalia }\end{array}$ & Invasão vascular & $\begin{array}{c}\text { Invasão de órgãos } \\
\text { adjacentes }\end{array}$ & $\begin{array}{c}\text { Metástases } \\
\text { intra- } \\
\text { abdominais } \\
\text { à distância }\end{array}$ \\
GCalculado & $10,89 *$ & $8,00 *$ & $9,75 *$ & 1,00 \\
GCrítico & 5,99 & 5,99 & 5,99 & 5,99 \\
\hline
\end{tabular}

Tabela 6 - Pacientes portadores de tumores renais, segundo a presença $(+)$ ou ausência (-) de invasão da gordura perirrenal, detectada pela tomografia computadorizada (TC) e ressonância magnética $(\mathbf{R M})$.

\begin{tabular}{ccccc}
\hline & \multicolumn{3}{c}{$\mathbf{R M}$} & \\
\cline { 2 - 3 } TC & + & - & TOTAL \\
+ & 18 & 1 & 19 \\
- & 0 & 12 & 12 \\
Total & $\mathbf{1 8}$ & $\mathbf{1 3}$ & 31 \\
\hline
\end{tabular}

Teste de McNemar

(Os resultados dispensam análise)

Porcentagem de + pela TC $=\frac{19}{31}=0,613$ ou $61,3 \%$

Porcentagem de + pela $R M=\frac{18}{31}=0,581$ ou $58,1 \%$ 
Tabela 7 - Resultado final obtido através do achado cirúrgico e exame anatomopatológico para a presença

(+) ou ausência (-) de adenomegalia, invasão vascular, invasão de gordura perirenal, invasão de órgãos adjacentes e metástases intra-abdominais à distância.*

\begin{tabular}{|c|c|c|c|c|c|}
\hline Paciente & Adenomegalia & $\begin{array}{l}\text { Invasão } \\
\text { vascular }\end{array}$ & $\begin{array}{c}\text { Invasão de } \\
\text { gordura } \\
\text { peri-Renal }\end{array}$ & $\begin{array}{l}\text { Metástases } \\
\text { de órgãos } \\
\text { adjacentes }\end{array}$ & $\begin{array}{l}\text { Intra- } \\
\text { abdominais à } \\
\text { distância }\end{array}$ \\
\hline$j$ & $\overline{-}$ & i & $\begin{array}{l}- \\
+\end{array}$ & - & - \\
\hline$\frac{1}{3}$ & $\begin{array}{l}T \\
-\end{array}$ & $\begin{array}{l}T \\
t\end{array}$ & - & - & t \\
\hline 4 & + & + & + & + & - \\
\hline 5 & $t$ & - & $t$ & - & - \\
\hline 6 & - & - & + & - & - \\
\hline 7 & + & + & $t$ & + & - \\
\hline 8 & - & - & - & - & - \\
\hline 9 & - & - & - & - & - \\
\hline 10 & - & - & - & - & - \\
\hline$\|$ & + & - & - & - & - \\
\hline 12 & $t$ & - & - & - & - \\
\hline $1 \overline{3}$ & - & - & - & - & - \\
\hline 14 & + & - & - & + & - \\
\hline 15 & - & - & - & - & - \\
\hline 16 & - & - & - & - & - \\
\hline 17 & - & - & + & + & - \\
\hline 18 & - & - & - & - & - \\
\hline 19 & + & - & - & - & - \\
\hline 20 & + & + & + & - & \\
\hline$\overline{2} \mid$ & + & + & + & + & + \\
\hline 22 & - & - & - & - & - \\
\hline 23 & - & - & + & - & + \\
\hline 24 & - & - & - & - & - \\
\hline 25 & - & - & - & - & - \\
\hline 26 & t & t & + & + & \\
\hline 27 & - & - & + & - & - \\
\hline $\begin{array}{l}28 \\
29\end{array}$ & - & - & t & - & + \\
\hline 30 & - & - & t & $\bar{t}$ & $\bar{t}$ \\
\hline 31 & - & - & - & - & - \\
\hline $\begin{array}{l}\text { TOTAL + } \\
\%+\end{array}$ & $\begin{array}{c}11 \\
35,5\end{array}$ & $\begin{array}{c}7 \\
22,6\end{array}$ & $\begin{array}{c}13 \\
41,9\end{array}$ & $\begin{array}{c}7 \\
22,6\end{array}$ & $\begin{array}{c}5 \\
17,2\end{array}$ \\
\hline
\end{tabular}

* Nos pacientes não operados ou com tumores irressecáveis, sem diagnóstico anatomopatológico, os achados concordantes pela TC e RM foram considerados verdadeiros. Achados discordantes ficaram como inconclusivos e não foram preenchidos.

intestinais por vezes dificultaram muito a avaliação do retroperitôneo central.

Apesar da baixa sensibilidade do US, sua especificidade foi muito elevada, não ocorrendo nenhum caso falso positivo, o que não deixa de ter sua importância já que em casos de dúvida pela TC quanto à presença e particularmente a extensão proximal de um trombo tumoral na veia cava, pode-se lançarmão do US, que é um método de fácil acesso, barato e não-invasivo.

O US tem vantagem sobre a TC em delinear a extensão tumoral para o interior do segmento retrohepático da veia cava inferior eátrio direito ${ }^{9,6}$. Em nossa casuística detectamos todos os casos de invasão da veia cava inferior nesta região proximal.

A RM também pode ser indicada nestas situações e em todas as outras em que haja qualquer dúvida quanto à presença e extensão do trombo tumoral, dada a sua elevada acurácia na detecção de envolvimento tumoral venoso $0^{6,7,10,11,12,13}$. A RM usando os planos sagital e coronal é particularmente útil na avaliação da extensão superior do trombo tumoral da veia cava relativamente ao diafragma, veias hepáticas e átrio direito 7,10 . A sensibilidade e especificidade para invasão tumoral venosa foram respectivamente $95 \%$ e $100 \%$ pela RM e $78 \%$ e $96 \%$ pela $\mathrm{TC}^{12}$. A sensibilidade e especificidade da RM na detecção de invasão vascular se aproxima de 100\% em várias séries $6,7,10,12$.

Na presente série, a TC e RM só não detectaram um dos sete casos de invasão venosa, em que havia invasão da porção proximal da veia renal, que foi interpretada como uma parte do tumor principal e não já uma extensão dele para o interior da veia. 
Houve também um caso falso-positivo, tanto pela TC quanto pela RM, em um paciente com um carcinoma de células transicionais grande que deformava o hilo renal, preenchendo a pelve e o ureter proximal que foi confundido com invasão da porção proximal da veia renal. Esta, na verdade, não era identificada, provavelmente por estar comprimida e deslocada pela massa (Fig. I).

Houve maior facilidade em se identificar a invasão venosa pela RM, tanto em função dos cortes multiplanares como pela fácil definição da existência ou não de um sinal anormal no interior dos vasos, os quais normalmente se apresentam sem qualquer sinal em seu interior tanto nas seqüências SE ponderadas em TI quanto em T2. Já a TC depende de uma boa e rápida injeção dinâmica do meio de contraste intravenoso e de aspectos nem sempre tão claros como descritos pela literatura ${ }^{5,6,7}$. Assim sendo, não há dúvidas de que a RM pode auxiliar em muitos casos de invasão vascular que não fiquem bem esclarecidos pela TC.

\section{Invasão da gordura peri-renal}

Os resultados do Teste de McNemar dispensam análise, ao mostrar que em somente um dos 3 I pacientes avaliados para a presença ou ausência de invasão da gordura peri-renal houve discordância entre a TC e RM. Apesar da elevada sensibilidade tanto da TC como da RM, detectando todos os casos de invasão da gordura peri-renal, houve um predomínio de erros falso-positivos, determinando uma especificidade relativamente baixa de ambos os métodos. Estesfalso-positivos são atribuídos a edema dos septos do tecido conectivo, hematomas organizados perinéfricos, necrose gordurosa, vasos sangüíneos colaterais dilatados ou fibrose por um processo inflamatório antigo ${ }^{5,6,7,11,14}$. Felizmente esta diferenciação tem pouca importância na abordagem cirúrgica.

\section{Invasão de órgãos adjacentes}

$O$ teste $G$ de Cochran mostrou discordância significante entre os métodos de diagnóstico por imagem no que diz respeito à detecção de invasão de órgãos adjacentes. Evidenciou que o US apresentou capacida-

Figura I - Invasão do ureter proximal simulando invasão da veia renal tanto pela TC (A) como na RM (B) devido a um carcinoma de células transicionais muito agressivo.

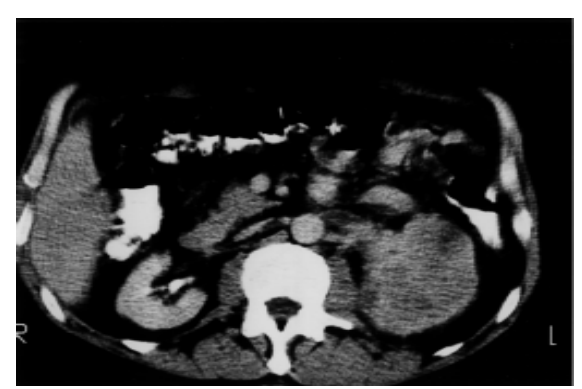

A

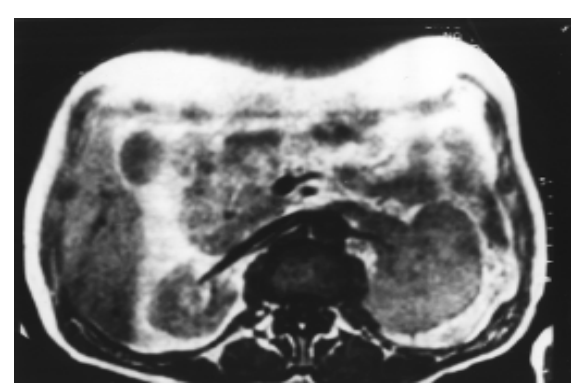

B

Figura 2 - TC pós-contraste evidencia grande tumor necrótico com importante espessamento da fáscia de Gerota e íntimo contato com o músculo psoas, não invadido. 0 cólon esquerdo, porém, se encontrava aderido ao tumor (seta).

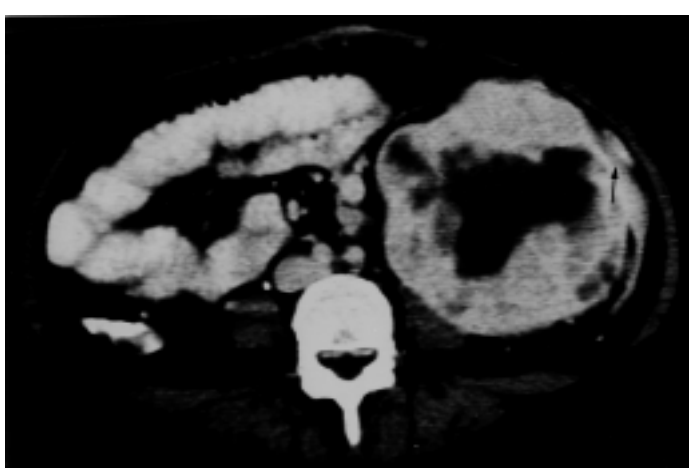

de de detecção significantemente menor do que a TC e RM, que não diferiram entre si.

Estes dados confirmam os achados de outros autores que mostram que o US tem sensibilidade significantemente menor que a TC 5,9 . Quanto à TC e RM, a maioria dos estudos referem capacidade semelhante destes exames ou uma superioridade da RM em função de realizar também cortes coronais e sagitais $5^{5,6,12}$.

Levine ${ }^{5,10}$ afirma que a perda aparente dos planos de gordura entre o tumor e estruturas adjacentes deve ser interpretada com precaução. Um grande tumor está não infreqüentemente aderido a um músculo ou órgão adjacente na ausência de extensão tumoral além da cápsula renal (Fig. 2). Inva- são de órgãos adjacentes na TC deve, portanto, ser sugerida somente quando a massa tumoral se estende para dentro dos órgãos adjacentes com uma aparência irregular e quando háalargamento ou mudança na densidade da estrutura adjacente. Embora tal invasão ocorra, ela é rara ${ }^{5,10}$. O fígado, em particular, representa um problema desde que algumas neoplasias do polo superior do rim $\mathrm{D}$ denteiam marcadamente a superfície caudal do fígado. Nesta situação, o US tem vantagens acima da TC em mostrar as verdadeiras relações de uma grande neoplasia do polo superior do rim $D$ com o fígado, na exclusão de invasão hepática direta sugerida pela TC por mostrar uma cápsula fibrosa intacta e plano de gordura 
separando o tumor e o fígado9,10 (Fig. 3).

Emtermos cirúrgicos, a invasão só estaria caracterizada nos casos em que a massa não pode ser dissecada da estrutura adjacente. Entretanto, no presente estudo, apesar de sete pacientes terem ficado com o diagnóstico final de invasão de órgãos adjacentes, apenas três destes foram operados e possuíam tumores que não puderam ser separados das estruturas vizinhas, infiltradas pelo câncer. Todas as demais lesões malignas operadas foram ressecadas, apesar de algumas aderências e mesmo infiltração de alças intestinais e outras estruturas que puderam ser dissecadas. Ainda assim, houve um predomínio de erros falso-positivos, três pela TC e dois pela RM.

O estadiamento completo da lesão é necessário para a conduta terapêutica apropriada, já que, nos pacientes em estadio IV de Robson ${ }^{2}$ )a sobrevida em cinco anos cai para cerca de $13,5 \%$ a $5 \%$, e para praticamente $0 \%$ em 10 anos $16,17,18$.

A literatura mostra que se deve sempre tentar a extirpação cirúrgica do tumor, o tanto quanto o estadiamento e as condições clínicas do paciente o permitam, dadas as repercussões positivas da conduta cirúrgica na melhoria do prognóstico do paciente, mesmo em tumores avançados ${ }^{5,15}$. Entretanto, é certo também que operar o paciente e não conseguir retirar um tumor localmente invasivo só poderá piorar as condições clínicas destes pacientes, geralmente já debilitados. Portanto, é de grande importância uma correta avaliação da invasão ou não das estruturas adjacentes, senão para eventualmente contraindicar uma cirurgia, pelo menos para indicar a embolização préoperatória nestes casos, na tentativa de reduzir as dimensões do tumor e melhorar as condições cirúrgicas.

Neste sentido, considerando somente os casos com diagnóstico cirúrgico comprobatório, procuramos estabelecer critérios de invasibilidade de tumores grandes e em estadio avançado, comparando os aspectos das massas irressecáveis com aqueles das massas ressecáveis.

Figura 3 -A) TC pós-contraste mostra imagem hipodensa irregular na base hepática que gerava dúvidas quanto a uma possível invasão em um paciente que apresentava um volumoso tumor no rim direito. Os cortes axial (B) e coronal (C) das seqüências $\mathrm{SE}$ ponderadas em TI da RM sugeriam invasão hepática, porém o US (D) definia corretamente um plano de clivagem com o fígado, não invadido.

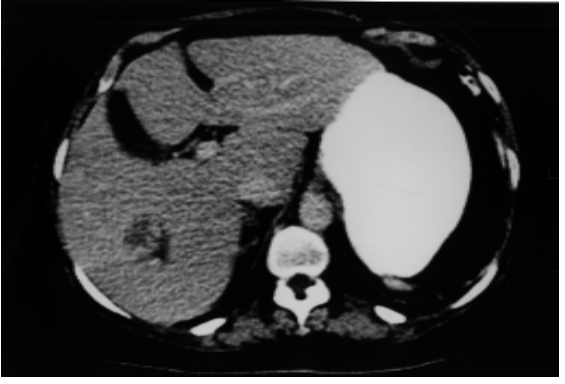

A

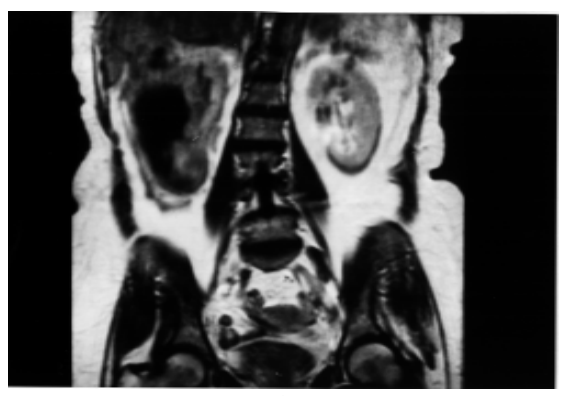

C

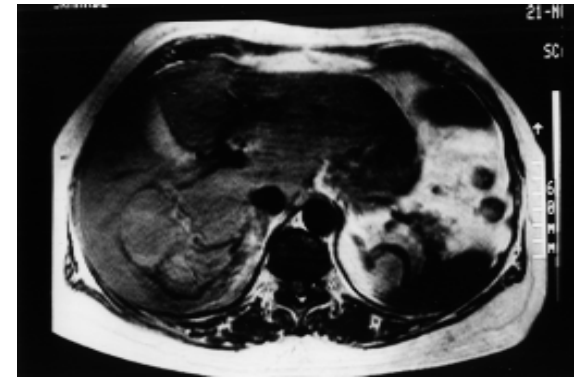

B

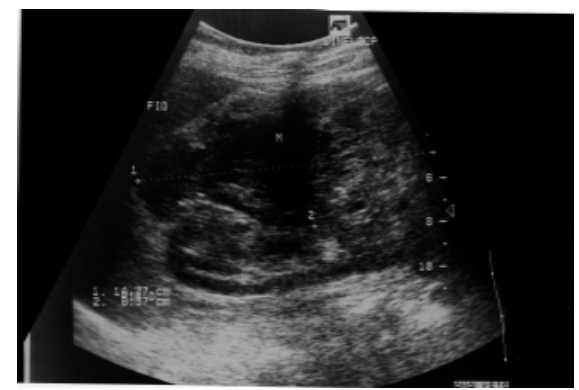

D

Figura 4 - TC pós-contraste evidencia massa muito heterogênea e de contornos irregulares, com envolvimento da gordura adjacente e que interrompe a luz do duodeno, sendo cirurgicamente irressecável. Observa-se ainda contato do tumor com o ângulo hepático do cólon, onde existiam aderências na cirurgia.

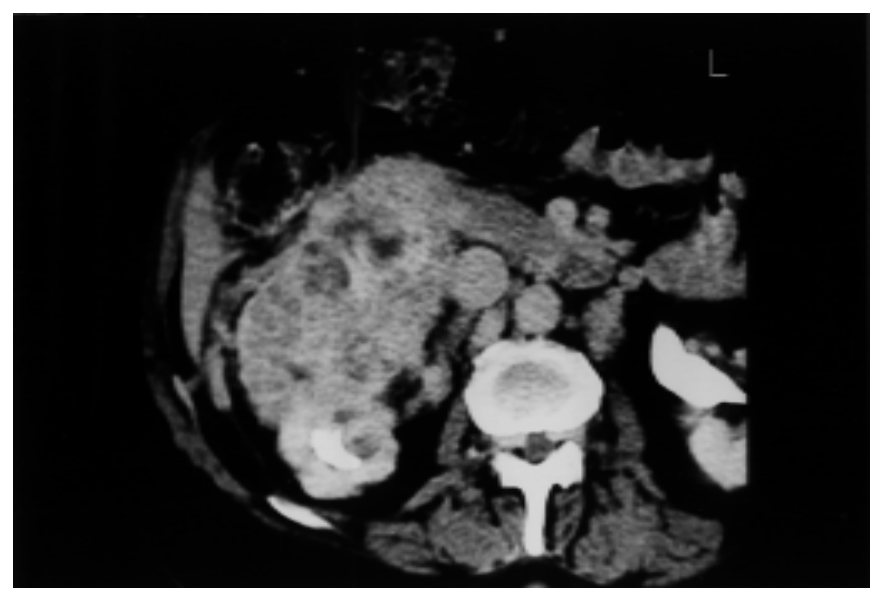


A perda do plano de gordura e o íntimo contato do tumor com a estrutura adjacente não indicam invasão, havendo necessidade de outros sinais, tais como: o envolvimento da estrutura pela massa, com tendência a englobá-la; a extensão da massa para o interior do órgão adjacente com aparência irregular. No caso específico das alças intestinais, o tumor deve interromper a luz intestinal (Fig. 4 e 5C). Somente o deslocamento e o íntimo contato não indicam invasão da alça intestinal. São também importantes as seguintes observações: uma superfície de contato entre o tumor e a estrutura invadida maior do que $5 \mathrm{~cm}$, média entre o maior tumor ressecável e o menor tumor irressecável da presente série. Alterações na forma, tamanho ou densidade da estrutura envolvida (Fig. 5D) e limites mal definidos (Fig. 5C). No caso do figado, notamos também uma alteração na sua densidade na TC, na forma de um halo hipodenso na fase sem contraste intravenoso, em uma região que, aparentemente, já não corresponde ao tumor, mas ao fígado, e que sofre realce ou torna-se isodensa a ele após a injeção intravenosa do contraste iodado (Fig. 5A e B e Fig. 6). A invasão hepática, porém, ainda por vezes será difícil de determinar pela TC e mesmo pela RM, e nestes casos o US ajuda muito na definição da presença ou não de invasão (Fig. 3).

\section{Conclusões}

A TC e RM apresentaram discordâncias significantes em relação ao US na detecção de adenomegalia, invasão vascular e invasão de órgãos adjacentes. O US apresentou uma capacidade de detecção significativamente menor do que a TC e RM, que não diferiram entre si. As diferenças de sensibilidade são importantes, tornando obrigatória a realização da TC ou RM para o estadiamento destes tumores. Já em relação às metástases intraabdominais à distância, não houve discordância significante entre o US, TC e RM e todos os três exames apresentaram sensibilidade e especificidade muito elevadas.

Figura 5 - TC do abdomen e pelve em um paciente que possuía um tumor maligno irressecável com $21 \mathrm{~cm}$ em seu diâmetro longitudinal. A lesão invadia o fígado, onde observamos halo hipodenso entre este e a massa $(A)$, que se realçou após injeção do contraste (B). C) A lesão, de limites mal definidos, se estende para o interior de alças intestinais com aparência irregular e envolve a veia cava inferior, ambos invadidos pelo tumor. D) Nota-se músculo psoas direito com formato alterado, mais estreitado, e com seu contorno externo de convexidade invertida pela invasão tumoral.

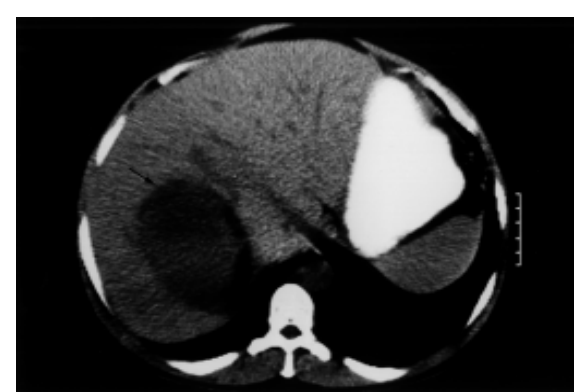

A

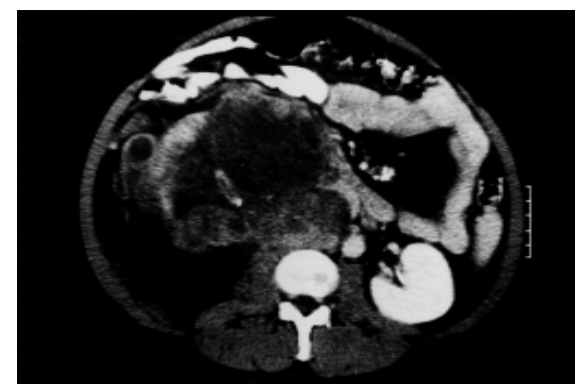

C

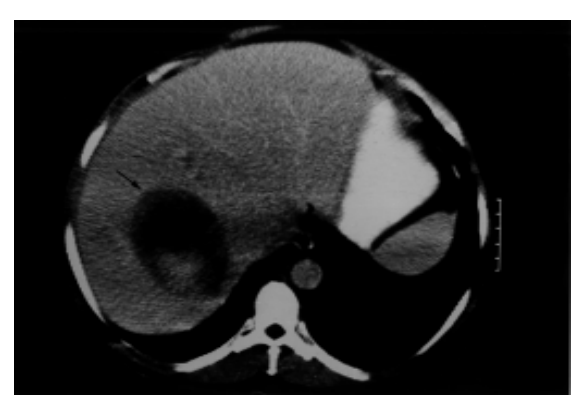

B

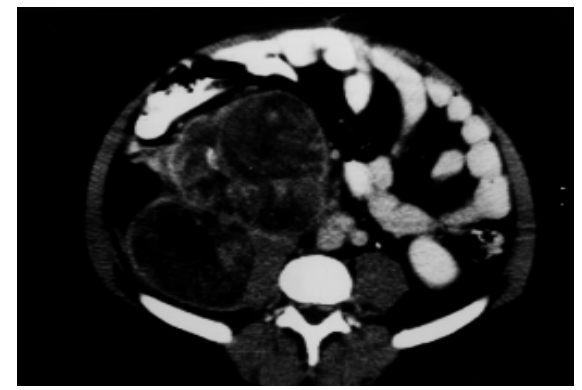

D
São critérios que sugerem fortemente a invasão de órgãos adjacentes por tumores renais malignos quando a massa tumoral envolve a estrutura invadida, tendendo a englobá-la; quando se estende para dentro do órgão adjacente com aparência irregular e limites mal definidos; quando interrompe a luz intestinal ou quando há alteração na forma, tamanho ou densidade da estrutura acometida. Também sugere invasão a observação de uma ampla superfície de contato entre o tumor e a estrutura invadida, maior do que $5 \mathrm{~cm}$. A perda do plano de gordura, o íntimo contato do tumor com a estrutura adjacente e o deslocamento desta não indicam invasão.

A RM é uma opção à TC nos pacientes que não possam receber contraste iodado intravenoso, assim como em situações específicas do estadiamento, esclarecendo principalmente casos onde existam dúvidas quanto à invasão vascular pelo US e TC $6,7,10,11,12,13$.

\section{Agradecimentos}

Agradecemos a colaboração do Dr. Dejaldo Marcos de Jesus Christofalo na análise dos exames.

\section{SUMMARY}

A COMPARATIVE STUDY OF ULTRASONOGRAPHY, COMPUTED TOMOGRAPHY AND MAGNETIC RESONANCE IMAGING IN THE STAGING AND INVASION OF ADJACENT STRUCTURES BY RENAL TUMORS 


\section{Figura 6 - Aspecto da invasão hepática pela TC antes $(A$ e $C)$ e após o contraste $(B)$ : Nota-se halo hipodenso entre o fígado e a massa renal que sofre realce após a injeção endovenosa do contraste iodado (setas). C) Neste paciente também se observa perda de defini- ção da parede tumoral na sua interface com o fígado.}

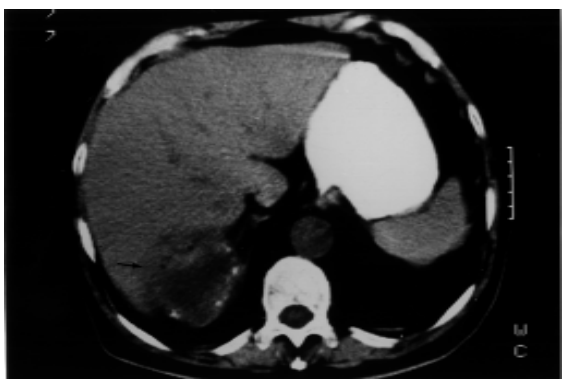

A

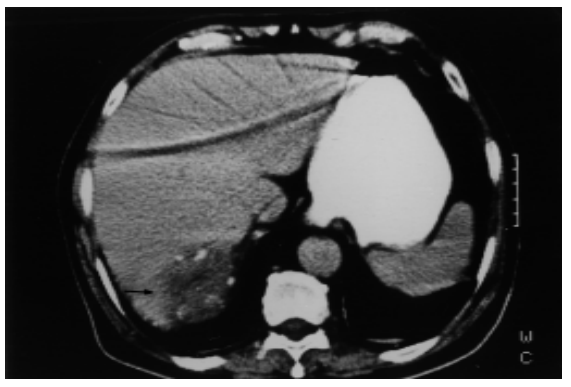

B

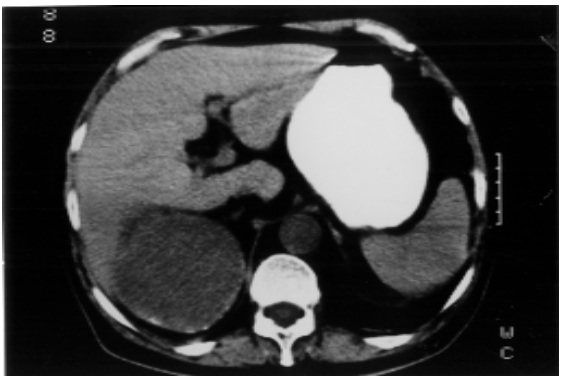

C
BACKGROUND. Ultrasonography (US), Computed Tomography (CT), and Magnetic Resonance imaging (MR) were compared for the staging of renal tumors. The differences between these imaging techniques were also studied for their ability to detect adenopathies, vascular invasion, distant intra-abdominal metastases, and particularly adjacent organ invasion.

MetHods. Thirty-one patients with solid or complex renal masses were prospectively studied using US, CT, and MR. Differences between the results obtained were studied using the COCHRAN G test and the MCNEMAR test. The sensitivity and specificity of each diagnostic technique were compared against a "gold standard" of the surgical and histopathological findings.

REsULTS. The following sensitivities were obtained: For the detection of adenopathy, US 63.6\%, CT and MR 90.9\%. For vascular invasion, US 42.8\%, CT and MR 85.7\%. For the adjacent organ invasion, US 28.5\%, CT $85.7 \%$, and MR $71.4 \%$. Some of the criteria that suggest invasion of adjacent structures include: the envelopment of the adjacent structures by the tumor, tumor extension into the adjacent structures with an irregular appearance, and alterations in shape, size, and density of adjacent structures. Loss of fat planes between the tumor and adjacent structures is not a sign of tumor invasion.
Conclusions. Significant differences were found in the detection capacity of US in relation to $C T$ and $M R$, which were similar. Allthree techniques were highly sensitive and specific only in the detection of distant abdominal metastases. In addition to the accuracy of these diagnostic modalities for the detection and staging of tumors, invasiveness, risks and cost should be considered in relation to relative costs and benefits. [Rev Ass Med Brasil 200 I ; 47(3): 198-207]

KEY WORDS: Kidney neoplasms. Neoplasm staging. Computed Tomography (CT). Magnetic Resonance (MR). Ultrasound (US).

\section{ReferênCIAS}

I. Ribeiro SM. Estudo comparativo dos métodos de imagem no diagnóstico e estadiamento dos tumores renais [tese]. São Paulo: Universidade Federal de São Paulo; 1997

2. Robson CJ, Churchill BM, Anderson W. The results of radical nefhrectomy for renal cell carcinoma. J Urol 1969; 101:297-30 I.

3. Siegel S. Estadistica no parametrica. México, Trillas, 1975.

4. Remington S, Schork MA. Statistics with aplications to biological and health sciences. NewJersey: Prentice-Hall, 1970.

5. Levine E. Malignant renal parenchymal tumors in adults. In: Pollack HM, editors. Clinical urography. Philadelphia: WB Saunders, 1990; 1216-91.

6. McClennan BL, Deyoe LA. The imaging evaluation of renal cell carcinoma: diagnosis and staging. Radiol Clin North Am 1994; 32:55-69.

7. Zagoria RJ, Bechtold RE, Dyer RB. Staging of renal adenocarcinoma: role of varions imaging procedures. AJR 1995; 1 64:367-70.

8. Lang EK. Comparison of dynamic and conventional computed tomography, angiography, and ultrasonography in staging of renal cell carcinoma.Cancer 1984; 54:2205- I 4.

9. Kuijpers D, Kruyt RH, Oudkerk M. Renal masses: value of duplex doppler ultrasound in the differential diagnosis. J Urol 1994; 1 5 1:326-8.

I0. Levine E. Renal cell carcinoma: Clinical aspects, imaging diagnosis and stading. Semin Roentgenol 1995; 30: 128-48.

I I. Heiken JP, Ling D, Glazea HS et al. Diagnosis and stading of renal cell carcinoma: a comparison of MR imaging and CT. AJR 1987; | 48:749-53.

12. Demas BE, Marotti M, Tanagho EA. Detection and staging of renal neoplasms: a reassessment of MR imaging. Radiology 1988; 166:643-9.

13. Lieskovsky G, Colletti PM, Boswell WD et al. Preoperative magnetic resonance imaging of veia cava tumor thrombi: experience with 5 cases. J Urol 1987; I38: | 220-2.

14. Levine E, Lee KR, Weigel J. Preoperative determination of abdominal extent of renal cell carcinoma by computed tomography. Radiology 1979; 132:395-8.

15. deKernion JB, Berry D. The diagnosis and treatment of renal cell carcinoma. Cancer 1980; 45: 1947-56.

16. McNichols DW, Segura JW, DeWeerd JH. Renal cell carcinoma: long-term survival and late recurrence. J Urol 1981; 126:17-22.

17. Sufrin G, Murphy GP. Renal adenocarcinoma. Surg Clin North Am 1982; 62: I 101.

18. Garnick MB. Renal cell carcinoma - Diagnostic workup and natural history. In: Garnick MB, Richie JP, editors. Urologic cancer. - A multidisciplinary perspective, 2nd ed. New York: Plenum Publishing, 1983; p.4I-9.

Artigo recebido: 31/05/00

Aceito para publicação: 16/03/01 